\title{
Pengaruh Faktor Sosial Ekonomi Petani Terhadap Produksi Usahatani Jagung Di Desa Rejuno Kecamatan Karangjati Kabupaten Ngawi
}

\author{
Rudy Bintoro Hari Larmintho \\ Program Studi Agroteknologi, Universitas Soerjo Ngawi, Jl. Cepu Km.3, Ngawi, 63218
}

E-mail: rudybintoro72@yahoo.co.id

\begin{abstract}
The purpose of this study was to determine the effect of socio-economic factors on corn farming production in Rejuno Village, Karangjati District, Ngawi Regency, East Java. The research was conducted in Rejuno Village, Karangjati District, Ngawi Regency, from October to December 2020. The population in this study were all maize farmers in Rejuno Village. The sampling technique in this study was using simple random sampling technique.

The results showed that (1) Corn farming in Rejuno Village, Karangjati District, Ngawi Regency was carried out in 4 (four) stages, namely land preparation and processing, planting was carried out twice per planting season, maintenance was carried out manually and harvesting was carried out manually; (2) Partially the variables of land area, seeds, and experience have a significant effect on maize farming production, while the number of family dependents and age have no significant effect on maize farming production. While simultaneously the variables of land area, seeds, labor force, experience, and age have a significant effect on the production of maize farming in Rejuno village, Karangjati sub-district, Ngawi district.
\end{abstract}

Keywords — : socio-economic factors; corn farming production.

\section{PENDAHULUAN}

Kebijakan pembangunan pertanian ditujukan untuk meningkatkan ketahanan pangan, mengembangkan agribisnis dan meningkatkan kesejahteraan petani, mengisyaratkan bahwa produk pertanian yang dihasilkan harus memenuhi syarat kuantitas, kualitas dan syarat keberlanjutan sehingga memiliki daya saing dan mudah diperoleh dengan harga yang terjangkau (Direktorat Serealia, 2003).

Pembangunan pertanian merupakan bagian yang tidak dapat dipisahkan dari pembangunan nasional, yang memiliki warna sentral karena berperan dalam meletakkan dasar yang kokoh bagi perekonomian negara. Hal ini ditunjukkan dari banyaknya penduduk atau tenaga kerja yang bekerja pada sektor pertanian. Hasil sensus pertanian tahun 2009 menunjukkan bahwa dari 237 juta penduduk Indonesia, sekitar 45,3 persen bekerja pada sektor pertanian. Sektor pertanian sangat diharapkan sebagai pemacu pertumbuhan ekonomi, baik sebagai penyedia atau sumber bahan baku industri maupun sektor andalan Indonesia selain minyak dan gas bumi (Badan Pusat Statistik Sumatera Barat, 2010).

Salah satu usaha untuk meningkatkan pertumbuhan ekonomi nasional di sektor pertanian adalah pada tanaman pangan dan hortikultura. Komoditas tanaman pangan dan hortikultura terdiri dari tanaman padi, palawija, sayur-sayuran, buah-buahan, tanaman hias serta tanaman obat yang dapat meningkatkan kesejahteraan, taraf hidup, serta kemampuan petani dalam sistem agribisnis dengan memanfaatkan keunggulan komparatif berupa iklim, kesesuaian dan kualitas lahan, ketersediaan tenaga kerja dan peluang pasar, baik di dalam maupun di luar negeri (Anonim, 1994).

Salah satu komoditi tanaman pangan yang cocok dan telah dibudidayakan oleh petani di Kabupaten Ngawi adalah jagung. Dewasa ini jagung tidak hanya digunakan untuk bahan pangan tetapi juga untuk pakan. Dalam beberapa tahun terakhir proposi penggunaan jagung oleh industri pakan telah mencapai 50\% dari total kebutuhan nasional. Dalam 20 tahun ke depan, penggunaan jagung untuk pakan diperkirakan terus meningkat dan bahkan setelah tahun 2020 lebih dari $60 \%$ dari total kebutuhan nasional.

Ditinjau dari sumberdaya lahan dan ketersediaan teknologi, Indonesia sebenarnya memiliki peluang untuk berswasembada jagung dan bahkan berpeluang pula menjadi pemasok di pasar dunia mengingat makin meningkatnya permintaan dan makin menipisnya volume jagung di pasar internasonal.

Upaya peningkatan produksi jagung di dalam negeri dapat ditempuh melalui perluasan areal tanam dan peningkatan produktivitas. Perluasan areal dapat diarahkan pada lahan-lahan potensial seperti lahan sawah irigasi, lahan sawah tadah hujan, dan lahan kering yang belum dimanfaatkan untuk pertanian. Berdasarkan penyebaran luas sawah dan tipe irigasinya, diperkirakan terdapat 457.163 ha yang potensial untuk peningkatan indeks pertanaman. Di luar Jawa terdapat 20,5 juta ha lahan kering yang dapat di-kembangkan untuk usahatani jagung.

Kune, (2017) melaporkan bahwa usahatani jagung memberikan tambahan pendapatan bagi petani dan memiliki keuntungan relatif yang lebih besar dari satu. Hal ini sejalan dengan Mardikanto, (1993) yang menyatakan bahwa pembangunan pertanian bertujuan untuk selalu memperbaiki mutu hidup dan kesejahteraan manusia terutama petani, baik perorangan maupun masyarakat pada umumnya dan Taena, (2009) yang menyatakan pemanfaatan sumberdaya pembangunan perlu diarahkan pada 
Website : http://agritek.unmermadiun.ac.id/index.php/agritek

suatu model pengembangan ekonomi wilayah perbatasan yang tepat agar dapat memaksimalkan kesejahteraan masyarakat. Untuk mempertahankan atau meningkatkan produksi usahatani jagung di Desa Rejuno maka perlu diketahui gambaran usahatani secara detail dan faktor sosial ekonomi yang berpengaruh. Faktor sosial ekonomi yang berpengaruh berbeda-beda antara komoditi pertanian yang diusahatanikan maupun faktor sosial ekonomi itu sendiri. Misalnya faktor-faktor yang mempengaruhi usahatani padi sawah di desa Haekto menurut Neonbota \& Kune, (2016) adalah pupuk, tenaga kerja dan modal sedangkan luas lahan, benih, pengalaman dan pendidikan tidak berpengaruh nyata. Hal ini berbeda pada komoditi sawi misalnya, menurut Usboko \& Fallo, (2016), luas lahan, bibit, pupuk kandang, dan jumlah tanggungan keluarga berpengaruh nyata terhadap produksi sawi, sedangkan curahan tenaga kerja, umur, dan pendidikan, tidak berpengaruh nyata.

Berbeda juga dengan pernyataan Bantaika, (2017) bahwa yang berpengaruh terhadap produksi usahatani jagung di Desa Tesi Ayofanu Kecamatan Kie Kabupaten Timor Tengah Selatan (TTS) hanya luas lahan dan benih. Dengan demikian maka perlu dilakukan kajian dengan topik "Pengaruh Faktor Sosial Ekonomi Petani terhadap Produksi Usahatani Jagung di Desa Rejuno, Kecamatan Karangjati, Kabupaten Ngawi, Jawa Timur, dengan tujuan untuk mengetahui 1) gambaran usahatani jagung; dan 2) faktor sosial ekonomi yang mempengaruhi usahatani jagung di desa Rejuno Kecamatan Karangjati Kabupaten Ngawi Jawa Timur.

\section{METODE PENELITIAN}

Penelitian dilaksanakan di Desa Rejuno, Kecamatan Karangjati, Kabupaten Ngawi, pada Bulan Oktober sampai Desember 2020. Populasi dalam penelitian ini adalah semua petani jagung di Desa Rejuno. Teknik pengambilan sampel dalam penelitian ini menggunakan teknik simple random sampling yaitu pengambilan sampel secara acak dimana setiap elemen dari populasinya mempunyai peluang yang sama-sama besar untuk terpilih ke dalam sampel. Data yang digunakan dalam penelitian ini adalah data primer yang diperoleh dengan teknik wawancara langsung dengan responden atau petani jagung di lokasi penelitian berdasarkan daftar pertanyaan yang disiapkan oleh peneliti sedangkan data sekunder diperoleh dari instansi atau lembaga terkait. Data yang diperoleh dikumpulkan kemudian ditabulasi dan dianalisis berdasarkan tujuan penelitian. Untuk menjawab tujuan pertama yaitu mengetahui gambaran umum produksi sawi manis peneliti menggunakan metode analisis deskriptif kualitatif sesuai petunjuk Sugiyono, (2006). Untuk menjawab tujuan kedua, dilakukan analisis maka digunakan analisis regresi linear berganda sesuai petunjuk Kurniawan, (2016) dengan model matematisnya sebagai berikut:

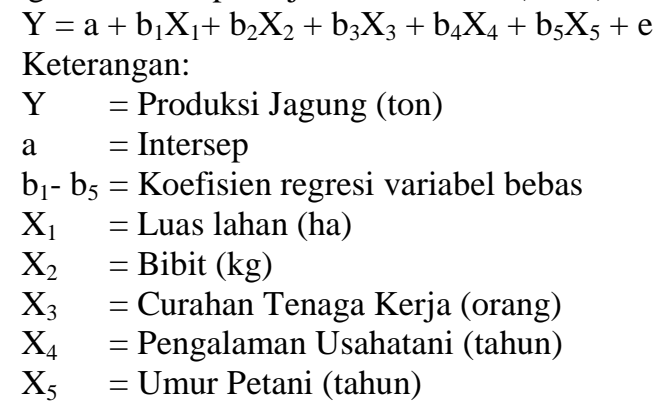

Data primer yang diperoleh dari hasil wawancara dengan responden diolah dengan menggunakan bantuan software SPSS versi 16.0.

\section{III.ANALISA DATA DAN PEMBAHASAN}

\section{A. Deskripsi Usahatani Jagung}

Usahatani jagung di di desa Rejuno Kecamatan Karangjati Kabupaten Ngawi meliputi beberapa tahapan kegiatan yaitu: Persiapan lahan, persiapan bibit dan pengolahan, penanaman, pemeliharaan (penyiangan), panen, dan pasca panen.

\section{Persiapan dan Pengolahan Lahan}

Kegiatan yang dilakukan dalam persiapan lahan dan pengolahan lahan berupa pembukaan lahan, penggemburan agar tanaman jagung memerlukan aerasi dan drainase yang baik. Di lokasi penelitian, tahap pertama yang dilakukan dalam persiapan lahan adalah pembukaan lahan. Kegiatan tersebut dilakukan karena lahan yang dapat dipakai untuk budidaya jagung merupakan lahan yang biasa ditumbuhi rerumputan liar. Kegiatan ini dapat dilakukan dengan cara tofa rumput atau membabat rumput- rumput liar lalu membakarnya. Pada umumnya petani lebih memilih untuk membabat lahan daripada membakar karena rumput yang dibabat tersebut dapat dipakai buat pupuk kompos.

2. Persiapan Bibit

Bibit termasuk salah satu faktor penentu keberhasilan dalam setiap usahatani tanaman. Penggunaan bibit yang bermutu tinggi akan dapat mengurangi risiko kegagalan usahatani. Bibit yang digunakan petani di Desa Rejuno adalah bibit jagung lokal. Jenis bibit yang digunakan petani di Desa Rejuno adalah jagung lokal dengan rata-rata 5,5 kg. tergantung pada luas lahan petani.

3. Penanaman

Faktor yang perlu diperhatikan dalam tahap penanaman adalah waktu tanam, jarak tanam dan cara tanam. Hasil penelitian menunjukkan bahwa bibit disediakan oleh petani. Waktu tanam untuk tanaman jagung dilakukan 2 kali musim 
Website : http://agritek.unmermadiun.ac.id/index.php/agritek

tanam yaitu batar ahuklean (jagung musim panjang) dan batar tinan (jagung umur pendek) yakni pada bulan DesemberMaret dan April-Juni. Penanaman bibit jagung dilakukan pada awal musim hujan, penanaman jagung dapat ditanam dengan menggunakan jarak tanam $75 \mathrm{~cm}$ x $70 \mathrm{~cm}$. Lubang dibuat sedalam 3-5 cm menggunakan tugal atau asuak setiap lubang diisi 2-3 biji jagung kemudian lubang ditutup dengan tanah.

4. Perawatan atau Pemeliharaan

Pada proses pemeliharaan merupakan kegiatan yang membutuhkan tenaga kerja dan tenaga kerjanya dalam keluarga. penyiangan dilakukan tergantung dari kondisi gulma dimana petani di daerah penelitian biasanya dilakukan secara manual yakni tofa dengan menggunakan tajak, kegiatan penyiangan dilakukan secara gotong royong. Kegiatan ini bertujuan untuk mengendalikan pertumbuhan gulma. Gulma atau rumput yang telah tercabut biasanya tidak langsung disingkirkan dari lahan, namun justru dikumpulkan dan ditumpuk di sekitar tanaman sehingga nantinya berubah menjadi kompos. Sedangkan masyarakat di lokasi penelitian tidak menggunakan pupuk kimia karena penggunaan pupuk kimia dianggap akan menurunkan kualitas tanaman jagung, mengurangi umur tanaman jagung, dan petani di Desa Rejuno juga mengalami keterbatasan biaya.

5. Panen dan Pasca Panen

Pemanenan jagung di daerah penelitian biasanya dilakukan setelah tanaman kira-kira berusia 3-4 bulan. Petani di lokasi penelitian biasanya melakukan panen dengan cara manual, yaitu jagung dipatah lalu dikumpulkan dan disusun ke dalam karung yang telah dipersiapkan petani agar bisa secara langsung dibawa pulang untuk di ikat lalu dijemur untuk simpan di tempat penyimpanan.

\section{B. Analisis Faktor-faktor yang Mempengaruhi Produksi Usahatani Jagung}

1. Hasil Analisis Parsial

Pengaruh parsial antara luas lahan (X1), bibit (X2), curahan tenaga kerja (X3), pengalaman (X4), dan umur (X5) terhadap produksi jagung (Y) dapat dilihat pada berikut ini.

Tabel 1. Hasil Analisis Parsial

\begin{tabular}{|c|c|c|c|c|c|c|}
\hline & & \multicolumn{2}{|c|}{$\begin{array}{c}\text { Unstandardized } \\
\text { Coefficients }\end{array}$} & \multirow{2}{*}{$\begin{array}{c}\begin{array}{c}\text { Standardized } \\
\text { Coefficients }\end{array} \\
\text { Beta }\end{array}$} & \multirow[b]{2}{*}{$\mathbf{t}$} & \multirow[b]{2}{*}{ Sig. } \\
\hline \multicolumn{2}{|c|}{ Model } & B & Std. Error & & & \\
\hline 1 & (Constant) & -1.568 & .680 & & -2.307 & .031 \\
\hline & luas lahan & 1.425 & .446 & .412 & 3.195 & .004 \\
\hline & bibit & .059 & .021 & .329 & 2.889 & .009 \\
\hline & curahan tenaga kerja & .156 & .039 & .317 & 3.983 & .001 \\
\hline & pengalaman & .029 & .027 & .086 & 1.052 & .305 \\
\hline & umur & .009 & .013 & .052 & .694 & .496 \\
\hline
\end{tabular}

a. Dependent Variable: produksi jagung

Berdasarkan Tabel 1 dapat diketahui bahwa nilai konstanta (a) regresi linier berganda sebesar -1,568, nilai koefisien regresi variabel luas lahan $\left(b_{1}\right)$ sebesar 1,425 , nilai koefisien regresi variabel bibit $\left(b_{2}\right)$ sebesar 0,059 , nilai koefisien regresi variabel curahan tenaga kerja $\left(b_{3}\right)$ sebesar 0,156 , nilai koefisien regresi variabel pengalaman $\left(b_{4}\right)$ sebesar 0,029 , dan nilai koefisien regresi variabel umur $\left(b_{5}\right)$ sebesar 0,009 . Persamaan regresi yang diperoleh dalam penelitian ini adalah sebagai berikut:

$\mathrm{Yi}=-1,568+1,425 \mathrm{X} 1+0,059 \mathrm{X} 2-0,156 \mathrm{X} 3-0,029 \mathrm{X} 4+0,009 \mathrm{X} 5$

Persamaan regresi yang diperoleh, menunjukkan bahwa faktor produksi yang mempengaruhi produksi jagung adalah:

a. Luas Lahan

Luas lahan berpengaruh nyata pada produksi jagung dengan taraf kepercayaan sebesar 5\%, dimana probabilitas $0,004<0,05$. Apabila luas lahan usahatani jagung bertambah 1 hektar maka produksi jagung akan meningkat sebesar 1,425 ton.

b. Bibit

Bibit berpengaruh nyata pada produksi jagung dengan taraf kepercayaan sebesar 5\%, dimana probabilitas 0,009 < 0,05. Apabila bibit jagung bertambah $1 \mathrm{~kg}$ maka produksi jagung akan meningkat sebesar 0,059 ton.

c. Curahan Tenaga Kerja

Curahan tenaga kerja tidak berpengaruh nyata terhadap produksi jagung pada tingkat kepercayaan 5\%, dimana probabilitasnya sebesar 0,001 >0,05. Apabila jumlah tenaga kerja bertambah 1 orang maka produksi jagung akan meningkkat sebesar 0,156 ton.

d. Pengalaman

Pengalaman usahatani jagung tidak berpengaruh nyata terhadap produksi jagung pada tingkat kepercayaan 5\%, dimana probabilitasnya sebesar $0.305>0,05$. Petani sulit untuk menerima inovasi baru yang dapat meningkatkan 
Website : http://agritek.unmermadiun.ac.id/index.php/agritek

produksi jagung, petani sudah merasa diri lebih berpengalaman dan nyaman dengan kondisi usahatani yang sudah dijalankan bertahun-tahun. Petani cenderung bertahan pada budaya cara berusahatani jagung yang sudah turun temurun dari nenek moyang.

e. Umur

Umur tidak berpengaruh nyata terhadap produksi jagung pada tingkat kepercayaan 5\%, dimana probabilitasnya sebesar 0,496>0,05. Hal ini berarti umur petani tidak berdampak positif pada peningkatan produksi jagung.

2. Hasil Analisis Simultan

Hasil uji F atau uji ANOVA menghasilkan F-hitung sebesar 47,920 > nilai F-tabel 2,684 atau nilai p-value $0,000<$ 0,05. Hal ini menunjukkan bahwa model regresi tersebut dapat digunakan untuk memprediksi produksi jagung (Y). Artinya variabel bebas luas lahan (X1), bibit (X2), curahan tenaga kerja (X3), pengalaman (X4) dan umur (X5) berpengaruh terhadap produksi jagung (Y). Maka dapat disimpulkan bahwa H1 diterima dan Ho ditolak. Hasil analisis regresi yang berpengaruh secara bersama-sama terhadap produksi jagung dapat dilihat pada Tabel 2.

Tabel 2. Hasil analisis Simultan

\begin{tabular}{|ll|r|r|r|r|r|}
\hline Model & & Sum of Squares & df & Mean Square & F & \multicolumn{1}{c|}{ Sig. } \\
\hline 1 & Regression & 31.351 & 5 & 6.270 & 47.920 & $.000^{\mathrm{a}}$ \\
& Residual & 2.748 & 21 & .131 & & \\
& Total & 34.098 & 26 & & & \\
\hline
\end{tabular}

a. Predictors: (Constant), umur, luas lahan, curahan tenaga kerja, pengalaman, bibit

b. Dependent Variable: produksi jagung

Berdasarkan Tabel 2 menunjukkan bahwa dengan tingkat kepercayaan 5\%, maka luas lahan (X1), bibit (X2), curahan tenaga kerja (X3), pengalaman (X4) dan umur (X5) secara bersama-sama berpengaruh terhadap produksi jagung pada petani jagung di Desa Rejuno Kecamatan Karangjati Kabupaten Ngawi.

\section{IV.KESIMPULAN}

Berdasarkan analisa data penelitian dapat disimpulkan hasil penelitian sebagai berikut:

1. Usahatani jagung di desa Rejuno Kecamatan Karangjati Kabupaten Ngawi dilakukan melalui 4 (empat), tahapan, yaitu (1) persiapan dan pengolahan lahan dengan cara tofa rumput atau membabat rumput-rumput liar lalu membakarnya; (2) penanaman dilakukan dua kali setiap musim tanam; (3) pemeliharaan dilakukan dengan cara manual yakni tofa rumput yang telah tumbuh lalu dikumpulkan dan ditumpuk di sekitar tanaman sehingga nantinya berubah menjadi kompos; (4) pemanenan dilakukan dengan manual yakni jagung dipatah dan dipisahkan dari tangkainya lalu dikumpulkan untuk diangkut ke tempat penyimpanan.

2. Secara parsial variabel luas lahan, bibit, dan pengalaman yang berpengaruh nyata terhadap produksi usahatani jagung, sedangkan jumlah tanggungan keluarga dan umur tidak berpengaruh nyata terhadap produksi usahatani jagung. Sedangkan secara simultan variabel Luas lahan, bibit, curahan tenaga kerja, pengalaman, dan umur berpengaruh nyata terhadap produksi usahatani jagung di desa Rejuno Kecamatan Karangjati Kabupaten Ngawi.

\section{UCAPAN TERIMAKASIH}

Ucapan terima kasih disampaikan kepada Pemerintah Kabupaten Ngawi dalam hal ini Kepala Dinas Pertanian dan Kepala Desa Renujo Kecamatan Karangjati Kabupaten Ngawi yang telah memberikan ijin dan membantu penulis pada saat melaksanakan penelitian. Kepada rekan-rekan dosen Universitas Soerjo Ngawi yang telah memberikan kontribusi dan saran guna penyempurnaan jurnal penelitian serta Rektor Universitas Soerjo Ngawi yang telah memberikan bantuan pendaan dalam kegiatan penelitian.

\section{DAFTAR PUSTAKA}

Ating, S. \& Sambas, A.M. 2006. Aplikasi Statistika Dalam Penelitian. Bandung: Penerbit Pustaka Setia.

Bantaika, Y. 2017. Faktor-Faktor yang Mempengaruhi Produksi Usahatani Jagung di Desa Tesi Ayofanu, Kecamatan Kie, Kabupaten Timor Tengah Selatan. AGRIMOR, 2(01): 10-11.

Bhato, M.A. 2016. Respon Pertumbuhan dan Hasil Jagung (Zea mays L.) Varietas Pioner terhadap Berbagai Takaran Pupuk Kandang Babi dan Jarak Tanam. Savana Cendana, 1(02): 85-89.

Badan Pusat Statistik Sumatera Barat, 2010

Badan Pussat Statistik Kabupaten Ngawi. 2019. Ngawi dalam Angka 2019.

Falo, M. \& Fallo, Y.M. 2016. Kajian Pendapatan Agroindustri Tortila di Kecamatan Insana Barat Kabupaten Timor Tengah Utara. AGRIMOR, 1(02): 19-20.

Kolo, D. \& Hutapea, A.N. 2016. Strategi Pengembangan Usaha Biskuit Jagung di Kelompok Wanita Tani Lestari Desa Subun Tua'lele, Kecamatan Insana Barat, Kabupaten Timor Tengah Utara. AGRIMOR, 1(03): 42-45.

Kune, S.J. 2017. Analisis Pendapatan dan Keuntungan Relatif Usahatani Jagung di Desa Bitefa Kecamatan Miomaffo Timur Kabupaten TTU. AGRIMOR, 2(02): 23-24.

Kurniawan, R. 2016. Analisis Regresi. Jakarta: Kencana.

Leki, W., Lelang, M.A. \& Taolin, R.I. 2016. Pengaruh Takaran Pupuk Kandang Sapi Terhadap Pertumbuhan dan Hasil Jagung (Zea mays, L.) yang Ditumpangsarikan dengan Kedelai (Glysine max,(L.) Merril). Savana Cendana, 1(01): 17-23. 
Website : http://agritek.unmermadiun.ac.id/index.php/agritek

Mardikanto, T. 1993. Penyuluhan Pembangunan Pertanian. Surakarta: Sebelas Maret University Press.

Neonbota, S.L. \& Kune, S.J. 2016. Faktor-Faktor yang Mempengaruhi Usahatani Padi Sawah di Desa Haekto, Kecamatan Noemuti Timur. AGRIMOR, 1(03): $32-35$.

Purwono \& Hartono 2008. Bertanam Jagung Unggul. Jakarta: Penebar Swadaya.

Sugiyono 2006. Metode Penelitian Kuantitatif, Kualitatif dan R \& D. Bandung: Alfabeta.

Taena, W. 2009. Kajian Pengembangan Ekonomi Wilayah Perbatasan Kabupaten Timor Tengah Utara dengan District Enclave Oekusi. Tesis. Institut Pertanian Bogor.

Usboko, A.M. \& Fallo, Y.M. 2016. Faktor Sosial Ekonomi yang Mempengaruhi Produksi Usahatani Sayuran Sawi di Kelompok Tani Mitra Timor. AGRIMOR, 1(03): 60-62.

Wonkay, R.E. \& Taolin, R.I.C.O. 2016. Pengaruh Model Penyimpanan Benih dan Jenis Pupuk Kandang terhadap Pertumbuhan dan Hasil Jagung (Zeamays L. ). Savana Cendana, 1(04): 128-132. 